\title{
Plasma corticosterone levels in the rat following discrete-trial discrimination or a single extinction trial
}

\author{
STEPHEN C. BRAKE, DAVID R. BURDETTE, and ABRAM AMSEL \\ The University of Texas at Austin, Austin, Texas 78712
}

\begin{abstract}
Male Sprague-Dawley rats received either successive discrimination training or continuous reward in a straight alley with a 24-h intertrial interval. Plasma corticosterone levels were determined after moderate (18 trials) and extended (46 trials) acquisition in Experiment I and after 20 trials in Experiment II. Increases in plasma corticosterone levels following nonreward in the discrimination groups or in subjects previously given $\mathbf{4 5}$ continuous reward trials were not significant relative to two control groups. These results fail to support the proposal that the pituitary-adrenal system is sensitive to downward reinforcement shifts (frustration effects) under widely spaced trials.
\end{abstract}

Experimental interest in the role of the pituitaryadrenal system in aversive conditioning (Levine, 1968; de Wied, 1967) has been extended within the last 4 years to instrumental appetitive conditioning. These latter experiments indicate (a) that increases in plasma corticosterone level (PCL) accompany the extinction of a water-reinforced response, and that there is a return to pre-extinction levels when the reinforcement contingency is reinstated (Coover, Goldman, \& Levine, 1971), and (b) that the pituitary-adrenal system is sensitive not only to decreases in frequency of reward, but also to increases in frequency of reward (Goldman, Coover, \& Levine, 1973).

Our purpose was to add to the information on adrenal functioning in appetitive situations by measuring pituitary-adrenal activity, as reflected by PCL, at various stages during acquisition of a discrete-trial successive discrimination and after sudden introduction of nonreward following continuous reward. We hoped by this procedure to provide a more analytic examination of the steroid response to reward withdrawal than is now available. Although Levine and his colleagues have suggested that increased pituitary-adrenal activity during extinction of an appetitive response may be a physiological response to frustrative nonreward (Levine, Goldman, \& Coover, 1972), it is unclear whether such activity is a response to the immediate consequence of reward withdrawal, the anticipation

This research was supported by Grant GB-14990X from the National Science Foundation. The authors wish to acknowledge their gratitude to Dr. Frank Bronson, Department of Zoology, University of Texas, Austin, for performing the corticosterone assay and to Dr. Delbert Theissen for reading an earlier version of this report. Reprint requests should be sent to: Abram Amsel, Department of Psychology, University of Texas at Austin, Austin, Texas 78712 . of such withdrawal, or both. In our own theorizing and research on the effects of reward withdrawal at the behavioral level, we have for some time found it useful to distinguish between primary and conditioned forms of frustration (Amsel, 1958, 1967). Exposure to nonreward ( $\mathrm{S}-$ ) after a number of rewards early in successive discrimination should elicit primary frustration $\left(\mathrm{R}_{\mathrm{F}}\right)$. Later in discrimination training, a nonrewarded trial should be an occasion for the appearance of conditioned (anticipatory) frustration $\left(r_{F}\right)$ to $S-$ along with some diminution of primary frustration resulting from nonreward (Amsel, 1962; Amsel \& Ward, 1965).

\section{EXPERIMENT I}

By measuring the PCL at different stages in the learning of a discrimination, and also following the introduction of nonreward after a number of continuous rewards in another condition, we hoped to obtain information relating the pituitaryadrenal response to both $R_{F}$ and $r_{F}$. A one-triala-day procedure made it possible to assess whether, in the presence of a large reward expectancy, a single nonrewarded trial is sufficient to activate the system.

\section{Method}

Subjects. The subjects were 70 male Holtzman albino rats, 90 days of age at the beginning of experimental treatment. They were individually housed in an isolated colony room under a 12-h light/dark cycle with light onset at $0700 \mathrm{~h}$. Beginning 10 days prior to runway training, subjects were fed $10 \mathrm{~g} /$ day at $1030 \mathrm{~h}$. After training had begun, each subject was fed $90 \pm 60 \mathrm{~min}$ following runway trials.

Apparatus. The apparatus consisted of two parallel alleys, one white, one black, both of which could be aligned with a common gray startbox measuring $27 \times 7.6 \times 7.6 \mathrm{~cm}$. Each alley had a $76-\mathrm{cm}$ runway, and a $30-\mathrm{cm}$ goalbox, both with internal dimensions of $7.6 \times 7.6 \mathrm{~cm}$. The entire 


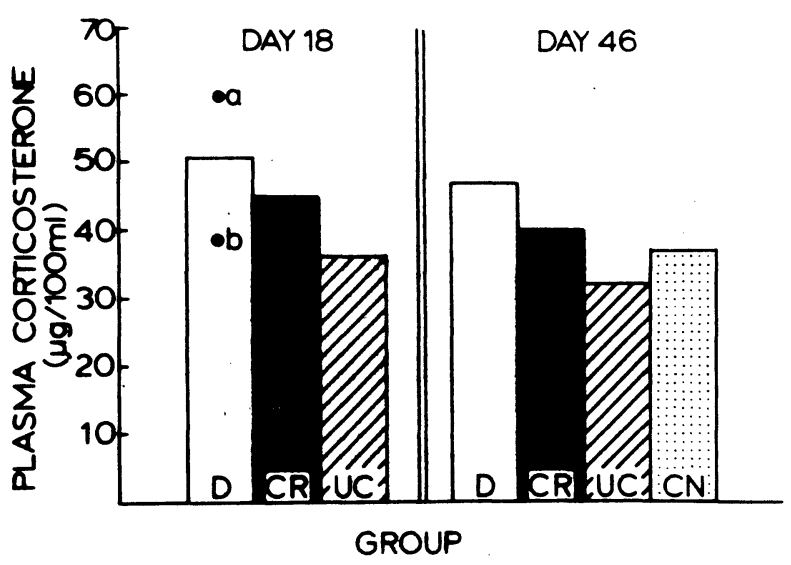

Figure 1. Mean plasma corticosterone of discrimination (D), continuous reward (CR), unhandled controls (UC), and continuous reward: nonreward (CN) groups on Day 18 and Day 46. Points $a$ and $b$ in Group D on Day 18 represent, respectively, subjects that did show evidence of behavioral discrimination and subjects that did not.

apparatus was covered with transparent Plexiglas. The startdoor was opaque Plexiglas, which, when raised, activated a microswitch that started the first of three Standard Electric timers. Interruption of three photobeams positioned at consecutive $30.7-\mathrm{cm}$ distances from the startdoor yielded start, run, and goal times, respectively. An aluminum door separated each alley from its respective goalbox. A foodcup, located $12.5 \mathrm{~cm}$ beyond the last photobeam and mounted on the back wall of each goalbox, was a semicircular sheet metal trough extending the width of the goalbox.

Procedure. Twenty rats were randomly assigned to each of three groups: discrimination (D), control (C), and unhandled control (UC). The remaining 10 subjects were assigned to a continuous reward: nonreward group $(C N)$. Subjects in Groups D, $C$, and $C N$ were run in the apparatus one trial a day. Reward when appropriate was one 500-mg Noyes pellet. Running order of subjects was randomized within and between days, with experimental training beginning each day at $0800 \mathrm{~h}, 1 \mathrm{~h}$ after light onset.

Group D was trained on a successive black $(\mathrm{S}+)$ /white $(\mathrm{S}-)$ discrimination. $\mathrm{S}+$ and $\mathrm{S}-$ trials occurred according to a predetermined quasirandom schedule, the only restriction being that a nonrewarded trial must occur on Day 18 and Day 46. Following Day 15, on which an S- trial occurred, Group D was split into two subgroups on the basis of alley performance. A two-tailed t test performed on total running speeds for Day 15 distinguished 10 rats which showed significantly suppressed running speeds compared to the preceding $\mathrm{S}+$ trial and thus had most obviously formed the discrimination, $t=5.68, \mathrm{df}=18, \mathrm{p}<.001$. These 10 subjects were assigned to D2, while the remaining 10 , which showed the least indication of having learned the discrimination, were assigned to D1. Runway training for D1 terminated on Trial 18; for D2 training terminated on Trial 46.

Group C was rewarded on every trial in the black alley. Following Day 15, 10 rats were randomly assigned to $C 1$ and the remaining 10 to $\mathrm{C} 2$. Runway training for subjects in Group $\mathrm{C} 1$ was terminated on Trial 18; for $C 2$, training terminated on Trial 46.

Subjects in Group CN received 45 rewarded trials, followed by a single nonrewarded trial on Day 46 , all in the black alley.

Subjects in Group UC remained undisturbed in their home cages. Ten animals were randomly assigned to UC1 and 10 to UC2 following Day 15, and these groups were sacrificed, as were the others, on Days 18 and 46, respectively.
The sequence of events comprising a trial for each rat in Groups D1, C1, D2, C2, and CN was as follows: Each was removed from its home cage located in an isolated room, carried by hand into an adjacent training room (a distance of $10 \mathrm{ft}$ ) and immediately placed in the startbox. As soon as the rat had oriented and moved toward the front of the startbox, the startdoor was raised. (After the initial few trials, subjects oriented almost immediately.) Upon breaking the last photobeam, the goalbox retrace door was lowered and the subject was confined for $30 \mathrm{sec}$ io the goalbox, during which time the food pellet was consumed on rewarded trials. The rat was then immediately returned to its home cage and fed about 90 min later.

Collection of blood samples was patterned after procedures described in Davidson, Jones, and Levine (1968). Fifteen minutes following return to its home cage on Day 18 or 46 , each rat was removed from its home cage, anesthetized with chloroform, decapitated, and $3 \mathrm{ml}$ of blood was collected. This entire sequence was completed within $75 \mathrm{sec}$ for each subject. Basal levels of corticosterone were obtained from unhandled controls by sacrificing them immediately upon removal from their home cages. With in $40 \mathrm{~min}$, the samples were centrifuged for $10 \mathrm{~min}$ and the plasma was stored on dry ice. The corticosterone assay, performed 30 days later employing a double-blind procedure, followed the fluorometric technique of Moncloa, Peron, and Dorfman (1959) as modified by Bronson and Eleftheriou (1965).

\section{Results}

D1 subjects as a group showed no evidence of discrimination. Subjects in Group D2 evidenced slower running speeds to $\mathrm{S}-$ at least by Day 10 and by Day 15 showed quite significant suppression to $\mathrm{S}-$. As in any successive discrimination, running speeds to $\mathrm{S}-$ in the latter part of training increased somewhat from their lowest levels and frequency of retraces decreased from their highest levels. The acquisition curves of subjects in Groups $\mathrm{C1}, \mathrm{C2}$, and $\mathrm{CN}$ were typical of those found with continuous reward training in the alley.

Plasma corticosterone levels (PCL) for Day 18 and Day 46 are shown in Figure 1. Analysis of variance performed on the data from both days combined and on each day separately indicated that the group differences were not significant. For Days 18 and 46 combined, $F(6,62)=2.09, p<.08$, and for Day 46 , $F(3,36)=2.66, p<.08$, analyses fell just short of significance. Two other $t$ test comparisons, D1 vs. UC1, $\mathrm{t}=2.28(18), \mathrm{p}<.02$, and $\mathrm{D} 2$ vs. UC2, $\mathrm{t}=2.13(18)$, $\mathrm{p}<.02$, were significant. However, the critical comparisons (D1 vs. $\mathrm{C} 1, \mathrm{D} 1$ vs. $\mathrm{Cl}$ and $\mathrm{UC1}$, D2 vs. C2) were, like the overall analysis of variance, nonsignificant. The null hypothesis, therefore, cannot be rejected. The failure to find an elevated PCL in Group $\mathrm{CN}$ indicates that a single exposure to nonreward following a large number of rewards may be insufficient to activate the pituitary-adrenal axis above basal functioning. The finding that D1 and D2 subjects did not show an elevated PCL suggests that repetition of nonrewarded trials at a minimum 24-h interval is also ineffective in elevating adrenal steroid levels. Contrary to our expectations, then, none of these procedures increased pituitary-adrenal activity. It is possible that within the limits of the discrete-trial 
procedure of the present study neither strong primary frustration, presumably present following an $\mathrm{N}$ trial in D1 subjects, nor weaker primary frustration together with anticipatory frustration, present following an $\mathrm{N}$ trial in D2 subjects, is sufficient to elevate corticosterone levels.

As a group, when sacrificed, the rats in D2 were showing clear behavioral discrimination in terms of divergence of speeds to $\mathrm{S}+$ and $\mathrm{S}-$, while those in D1 were not. However, closer examination of individual subjects in D1 indicated that three of them had begun to discriminate by Day 18. A one-tailed $t$ test revealed that the running speeds for these three subjects were significantly slower on Day 18 than were the speeds of the seven remaining $D 2$ subjects, $t=2.68(8), p<.02$. We had expected that the more intense primary frustration presumably experienced immediately following nonreward ( $N$ trials) by subjects not yet discriminating would, if anything, produce a higher PCL than in those beginning to discriminate (Amsel \& Ward, 1965). There was, however, an indication of the reverse (compare Points a and b in Figure 1), that is to say a higher PCL in the three D1 subjects who displayed differential behavior to $\mathrm{S}+$ and $\mathrm{S}-$ (Point a) than in those who did not (Point b). To determine whether increased pituitary-adrenal activity might be related to a behavioral response indicative of $\mathrm{S}$ aversiveness, the corticosterone levels of the Di(a) subjects were considered separately from the six nondiscriminating D1(b) subjects (one D1 score was lost during the assay procedure). Analyses of the differences proved to be nonsignificant. However, an $F$ test comparing the D1(a) subjects, the $C 1$ subjects, and the UCl subjects fell just short of significance, $\mathrm{F}(2,20)=3.39, \mathrm{p}<.06 ;$ and a one-tailed $\mathrm{t}$ test comparing D1(a) with $\mathrm{Cl}$ proved significant, $\mathrm{t}=$ $2.42(11), \mathrm{p}<.02$. There is then a suggestion that those D1 subjects whose behavior indicated an anticipation of nonreward showed a higher PCL.

\section{EXPERIMENT II}

In Experiment II, we investigated further the possibility, raised in Experiment I, that the earliest signs of behavioral discrimination are correlated with increased pituitary-adrenal activity and that both effects may be related to the underlying associative processes responsible for differential responding to $\mathrm{S}-$.

\section{Method}

Subjects. These were 25 male Holtzman albino rats, 90 days of age. and were given pretraining treatment identical to that of Experiment $\mathrm{I}$.

Apparatus. The apparatus used was the same as in Experiment I.

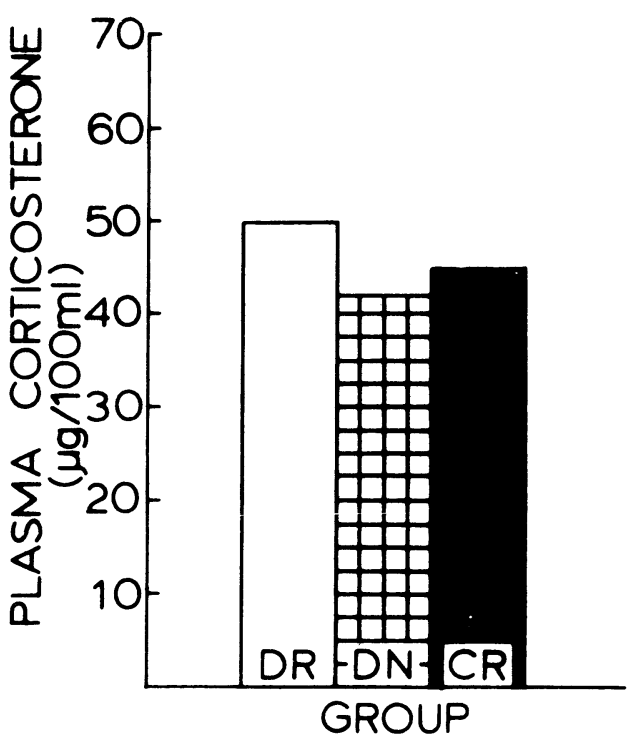

Figure 2. Mean plasma corticosterone obtained in Experiment II of discrimination subjects that retraced (DR) or did not retrace (DN) on Day 20 and the continuous reward (CR) group.

Procedure. Two groups of rats. Group $C(n=10)$ and Group D $(n=15)$, were trained and sacrificed in a manner similar to Groups $\mathrm{C} 1$ and D1, respectively, of Experiment $\mathrm{I}$. The only procedural difference in this experiment was that 20 trials, one trial/day, rather than 18 trials, were run in order to increase the percentage of subjects showing evidence of having formed the discrimination by the time blood samples were collected. As in Experiment I, the final trial for D1 animals was nonrewarded.

\section{Results}

As in Experiment $I$, the D subjects as a group had not learned the discrimination, although an examination of individual-subject data showed that seven of them (Group DR) showed behavioral aversion to $\mathrm{S}-$ as indicated by slower running speeds, $\mathrm{t}=7.19(13), \mathrm{p}<.001$, and increased retracing in the alley compared to the remaining eight subjects (Group DN). Corticosterone data are shown in Figure 2. No statistically significant differences were found in any of the comparisons. Statistical analysis was also performed on discrimination and control groups formed by combining the data of Experiments I and II. There were no significant group effects in these comparisons either. The suggestion that those Group D rats showing behavioral aversion to $\mathrm{S}$ - also experience increased pituitary-adrenal activity, resulting in an elevated PCL, was not confirmed.

\section{DISCUSSION}

Levine, Goldman, and Coover (1973) have proposed that activation of the neuroendocrine systems leading to the subsequent release of ACTH may result from a change in the organism's 
established expectancies. It is unclear, however, whether by "change in expectancies" they meant the occurrence of a single event contrary to an established expectancy or the establishment of a new expectancy (anticipation). The current results do not clearly support either of these possibilities, at least in a discrete trial procedure. It should, however, be pointed out that, although the PCL differences were nonsignificant in many of the analyses, they were in the expected direction. In Experiment I, they often fell just short of significance. In fact, some of our PCL comparisons (D1 vs. UC1, D1(a) vs. C1, D2 vs. UC2) show differences comparable to those found by Coover et al. (1971) and Goldman et al. (1973). The fact that we failed to find significance in several critical comparisons in Experiment $I$, or in any comparison in Experiment II, might be attributable to the high degree of individual variability in our data and/or the unusually high PCLs of our control groups.

There are many procedural differences between our study and the earlier ones that could account for these differences in results. One possibility is that in the operant procedure employed by Coover et al. and Goldman et al., the effects of several, rapid, successive exposures to nonreward might produce larger PCLs through summation of primary and secondary frustration than did our discretetrial procedure. Another obvious difference between the studies involves the type and duration of deprivation schedules. Both Coover et al. and Goldman et al. employed water deprivation, and Coover et al. allowed a prolonged (30-day) adaptation period to the maintenance schedule. We employed food deprivation and a 10-day adaptation period, and our control group PCLs were approximately twice as high as the levels reported in the other studies. The level of food deprivation in our experiments may have been stressful enough to raise the PCL of all our groups, making it difficult, with the operation of a possible ceiling effect, to demonstrate any additional elevations resulting from the experimental manipulations. In this connection, both positive (Garrud, Gray, \& de Wied, 1974; Gray, 1971; Guth, Levine, \& Seward, 1971; Hennessy, Cohen, \& Rosen, 1973) and negative (Levine, 1968; Miller \& Caul, 1973) results on the role of exogenous ACTH or corticosterone on appetitive extinction have been found, and this state of affairs may be due in part to the type, duration, and/or severity of deprivation. Relatively high levels of ACTH in control groups obviously reduce the likelihood of detecting an elevated PCL following nonreward, or of obtaining differential extinction effects through the injection of ACTH.

Although we have been unable to perform the relevant studies bearing on this point, two studies in the literature provide useful information regarding deprivation and corticosterone levels. Johnson and Levine (1973) report that allowing female rats access to water for $1 \mathrm{~h}$ or less at 1000 or $1500 \mathrm{~h}$ disrupts the cyclicity of the corticosterone response and displaces the peak of the rhythm to the period just prior to scheduled watering. Similarly, Krieger (1974) has found that rats deprived of both food and water show increases in PCL prior to feeding when measured against the normally low corticosterone levels present during the hours following light onset. Such deprivation-induced elevations could conceivably mask effects due to previously administered experimental treatments. It is interesting that the control PCLs in the Coover et al. and Goldman et al. studies were indeed approximately the same as those in the experiments of Johnson and Levine and Krieger. It should be noted, however, that the deprivation schedule we used was probably more severe than the 22 -h schedule used by Krieger. Thus, the combined effect of the possibly greater deprivation-induced PCL elevations in all groups and the relatively mild single-trial procedure could have resulted in rather small experimental PCL increases in our experiments.

\section{REFERENCES}

AMSEL, A. The role of frustrative nonreward in non-continuous reward situations. Psychological Bulletin, 1958, 55, 102-119.

AMSEL, A. Frustrative nonreward in partial reinforcement and discrimination learning: Some recent history and a theoretical extension. Psychological Review, 1962, 69, 306-328.

AMSEL, A. Partial reinforcement effects on vigor and persistence. In K. W. Spence \& J. T. Spence (Eds.), The psychology of learning and motivation (Vol. 1). New York: Academic Press. 1967.

Amsel, A., \& WARD, J. S. Frustration and persistence: Resistance to discrimination following prior experience with the discriminanda. Psychological Monographs, 1965, 79, 1-41.

Bronson, F. H., \& Eleftheriou, B. E. Relative effects of fighting on bound and unbound corticosterone in mice. Proceedings of the Society of Experimental Biology and Medicine, 1965, 118, 146-149.

Coover, G. D., Goldman, L., \& Levine, S. Plasma corticosterone increases produced by extinction of operant behavior in rats. Physiology and Behavior, 1971, 6, 261-263.

Davidson, J. M., Jones, L. E., \& Levine, S. Feedback regulation of adrenocorticotropin secretion in "basal" and "stress" conditions: acute and chronic effects of intrahypothalamic corticoid implantation. Endocrinology, 1968, 82, 655-663.

DE WIED, D. Opposite effects of ACTH and glucocorticosteroids on extinction of conditioned avoidance behavior. In: L. Martini, F. Franschini, \& M. Motta (Eds.), Hormonal Steroids. The Hague: Mouton, 1967.

Garrud, P., Gray, J. A., \& DE Wied, D. Pituitary-adrenal hormones and extinction of rewarded behavior in the rat. Physiology and Behavior, 1974, 12, 109-119.

Goldman, L., Coover, G. D., \& Levine, S. Bidirectional effects of reinforcement shifts on pituitary adrenal activity. Physiology and Behavior, 1973, 10, 209-214.

GRAY, J. A. Effect of ACTH on extinction of rewarded behavior 
is blocked by previous administration of ACTH. Nature (London), 1971, 229, 52-54.

Guth, S., Levine, S., \& Seward, J. P. Appetitive acquisition and extinction with exogenous ACTH. Physiology and Behavior. 1971, 7, 195-200.

Hennessy, J. W., Cohen, M. E., \& Rosen, A. J. Adrenocortical influences upon the extinction of an appetitive runway response. Physiology and Behavior, 1973, 11, 767-770.

Johnson, J. T., \& LEvine, S. Influence of water deprivation on adrenocortical rhythms. Neuroendocrinology, 1973, 11, 268-273.

KRIEGER, D. T. Food and water restriction shifts corticosterone, temperature, activity and brain amine periodicity. Endocrinology, 1974, 95, 1195-1201.

LEVINE, S. Hormones and conditioning. In W. J. Arnold
Ed.), Nebraska Symposium on Motivation. Lincoln, Nebraska: University of Nebraska Press, 1968.

Levine, S., Goldman, L., \& Coover, G. D. Expectancy and the pituitary-adrenal system. In Physiology, emotion, and psychosomatic illness. Amsterdam: Elsevier, 1972.

Miller, R. E., \& Caul, W. F. Effect of adrenocorticotropic hormone on appetitive discrimination learning in the rat. Physiology and Behavior, 1973, 10, 141-143.

Moncloa, F., Peron, F. G., \& Dorfman, R. I. The fluorimetric determination of corticosterone in rat adrenal tissue and plasma: Effect of administration of ACTH subcutaneously. Journal of Endocrinology, 1959, 65, 717-724.

(Received for publication February 11, 1975; accepted December 4, 1975.) 